\title{
Chronische Lebererkrankungen Fettleber bahnt der Zirrhose den Weg
}

\author{
Die Fettleber ist keineswegs so harmlos, wie lange angenommen. \\ Die Lipidakkumulation ist vielmehr ein direkter Wegbereiter der \\ Leberzirrhose und kann damit sogar im Leberkrebs münden.
}

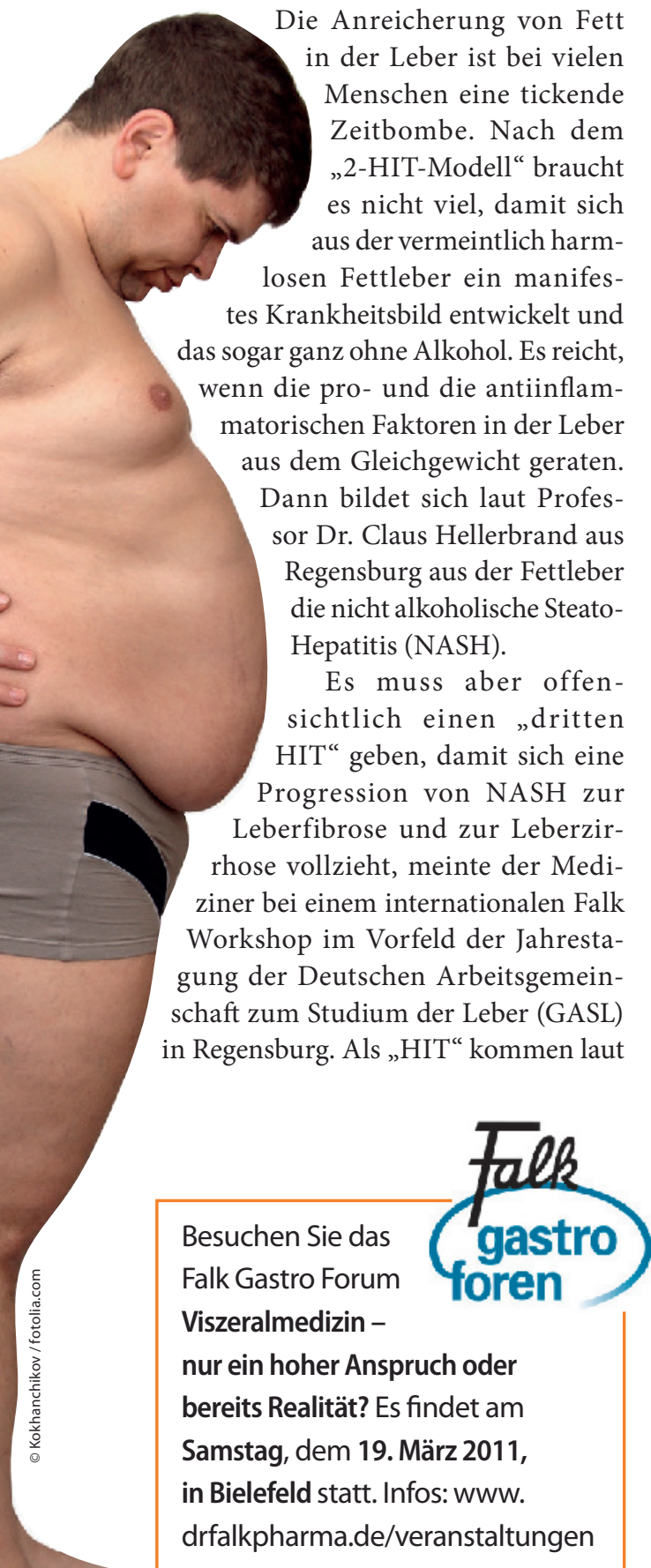

Hellerbrand vor allem die Faktoren des metabolischen Syndroms in Betracht, allen voran das Übergewicht respektive die Adipositas und die Insulinresistenz.

\section{Turbofaktor Alkohol}

Insbesondere das viszerale Fett ist Gift für die Leber. Denn in den Adipozyten ist die Bildung des hepatoprotektiven und antifibrotisch wirksamen Adiponectin vermindert, während andererseits reichlich profibrogenes Leptin ausgeschüttet wird. Außerdem verändert die Adipositas die intestinale Flora, was eine vermehrte Translokation von Keimen und bakteriel- len Komponenten in die Leber zur Folge hat. „Das kann ein weiterer Faktor sein, der die Progression zur Fibrose triggert", betonte Hellerbrand. Kommt der „Faktor Alkohol“ hinzu, dann beschleunigt sich der pathogenetische Prozess enorm.

Auch davon abgesehen, ist die Fettleber nicht ohne: „Die Fettakkumulation aktiviert das Enzym CYP2E1, was eine vermehrte Bildung reaktiver Sauerstoffspezies nach sich zieht und Regenerationsprozesse in der Leber hemmt. Das alles kann, so Hellerbrand, den rutschigen Weg von der Steatose über die Steatohepatitis in die Fibrose und Zirrhose noch schlüpfriger machen. (Christine Vetter)

\section{Autoimmunhepatitis: Steroidtherapie ohne Mondgesicht und Stiernacken}

Patienten mit einer Autoimmunhepatitis (AIH) brauchen meist lebenslang eine immunsuppressive Therapie. „Umso wichtiger ist es, dass wir alles tun, um die Nebenwirkungen der Steroidgabe zu minimieren", mahnte Professor Dr. Michael Manns aus Hannover beim Falk Workshop in Regensburg.

Realisieren lässt sich das Ziel durch eine Behandlung mit Budesonid*, ein infolge seines hohen First-Pass-Effektes in der Leber quasi lokal wirksames Steroid. Das belegt laut Manns eine prospektive Multicenterstudie bei 207 AIH-Patienten, die damit die größte Studie dieser Art bei der AIH darstellt. Gezeigt wurde, dass Budesonid hinsichtlich der Remissionsinduktion mindestens ebenso effektiv ist wie
Prednisolon (Prüfparameter: Normalisierung der Leberwerte) und bei der Erhaltungstherapie sogar deutliche Vorteile bietet. So waren nach zwölf Monaten 60,2\% der Patienten, die initial Budesonid (Budenofalk ${ }^{\circledast}$ ) erhalten hatten, mit ihren Leberwerten im Normbereich, ohne steroidtypische Nebenwirkungen aufzuweisen. In der Patientengruppe mit anfänglicher Prednisolongabe wurde das nur bei 49,4\% gesehen.

Beeindruckend war ein weiteres Studienergebnis: Bei Patienten, die nach sechs Monaten von Prednisolon auf Budesonid wechselten, reduzierte sich die Rate an Steroidnebenwirkungen von 40,2 auf 18,4\%.

${ }^{*}$ Budenofalk ${ }^{\circledast}$ ist noch nicht zugelassen bei AlH und darf nicht bei Leberzirrhose gegeben werden. 